\title{
A rat model of Parkinson's disease induced by Japanese encephalitis virus
}

\author{
Akihiko Ogata $^{1}$, Kunio Tashiro ${ }^{1}$, Souichi Nukuzuma ${ }^{2}$, Kazuo Nagashima ${ }^{2}$ and William W Hall ${ }^{3}$ \\ Departments of ${ }^{1}$ Neurology and ${ }^{2}$ Pathology, Hokkaido University School of Medicine, North-14, West-5, Kita-ku, \\ Sapporo, 060, Japan; ${ }^{3}$ Laboratory of Medical Virology, The Rockefeller University, 1230 York Avenue, New York, NY \\ 10021-6399, USA
}

\begin{abstract}
In Fischer rats infected with Japanese encephalitis virus (JEV) at 13 days after birth and sacrificed 12 weeks later, the major pathological changes resembled those found in Parkinson's disease. Specifically there was neuronal loss with gliosis which was confined mainly to the zona compacta of the substantia nigra, with a notable absence of lesions in the cerebral cortex and cerebellum. Changes were bilateral being most severe in the central part of the zona compacta. Immunohistochemical studies with anti-tyrosine hydroxylase (TH) demonstrated that the number of TH-positive neurons was significantly decreased in the substantia nigra compared to controls, while comparable numbers of TH-positive neurons were found in the basal ganglia in both JEVtreated rats and age-matched controls. JEV-infected rats showed marked bradykinesia, with significant behavioral improvement being observed following administration of L-DOPA. Immunohistochemical studies failed to detect JEV antigens in any region of the rat brain and the JEV genome was undetectable in the substantia nigra and the cerebral cortex using the reverse transcription-polymerase chain reaction (RT - PCR). The findings suggest that JEV infection of rats under the conditions described may serve as a model of virus induced Parkinson's Disease.
\end{abstract}

Keywords: brain; Japanese encephalitis virus; parkinsonism; substantia nigra; viral tropism

\section{Introduction}

The development of experimental models of Parkinson's Disease have in most instances involved the administration of drugs or following acute viral infections. The most widely used model is that induced by the metabolites of 1-methyl-4phenyl-1,2,3,6-tetrahydropyridine (MPTP) (Langston et al, 1983; Burns et al, 1983; Ballard et al, 1985). Neuropathologic findings in MPTP-treated monkeys are similar to those of Parkinson's disease in that neurons in the substantia nigra are primarily involved, while other structures of the basal ganglia are spared. Despite these similarities, MPTP-induced parkinsonism does differ from the human disease in several respects (Langston et al, 1983; Ballard et al, 1985; Langston, 1989) and the model is limited in that disease is induced only minimally or not at all in small animal species, including rats (Chiueh et al, 1983; Heikkila et al, 1984). A second

Correspondence: A Ogata

Received 11 December 1995; revised 12 September 1996; accepted 1 November 1996 drug associated model of parkinsonism, which involves the stereotactic injection of 6-hydroxydopamine into the substantia nigra, is severely limited by technical difficulties (Kelly et al, 1975). Virusinduced models of Parkinson's disease have been reported following infection with both corona-virus (Fishman et al, 1985) and influenza virus (Takahashi et al, 1995). In this report we describe the development of pathological and certain clinical features consistent with Parkinson's disease following inoculation of Japanese encephalitis virus (JEV). We have previously described the pathological features and distribution of JEV antigens in developing rat brain after intracerebral virus inoculation (Ogata et al, 1991). In these studies it could be shown that in general the susceptibility of rat brain to JEV infection was dependent on the age of animals at the time of infection and this appeared to be related to the level of neuronal maturity. Of note it could be shown that neurons of basal ganglia and substantia nigra remained much more susceptible to infection than those of the cerebral cortex (Ogata et al, 1991). Specifically animals infected at $1-3$ days 
of age developed widespread infection throughout the brain, whereas in animals infected at age 10 days, JEV antigen became almost undetectable in the cerebral cortex and by 14-day-old rats JEV antigen was essentially restricted to the basal ganglia and substantia nigra (Ogata et al, 1991). The limitation of infection to these areas suggested that infection of rats between days 12 and 14 after birth may result in pathological and clinical processes which might resemble Parkinson's disease. In the present study we describe the pathological and virological features of such infections and show that this in fact does serve as a useful model of Parkinson's disease.

\section{Results}

Neuropathologic studies

In control studies, 13-day-old animals infected with JEV were sacrificed 3 days later and JEV antigen was found primarily in the substantia nigra and the caudate putamen in a distribution similar to that previously described (Ogata et al, 1991). Strikingly the expression of JEV antigen was localized to neurons in the substantia nigra (Figure 1, arrows). In contrast, JEV antigen could not be detected in brains of the rats sacrificed at 10 days, 12 weeks and one year after infection. Pathological examination showed that in adult rats infected with JEV at the age of 13 days, neuronal loss was confined mainly to the zona compacta of the substantia nigra. No lesions were observed in the cerebral cortex or cerebellum (Figure 2a and b). Furthermore, the most severe lesions were found in the central part of the zona compacta, with the lateral cell groups being

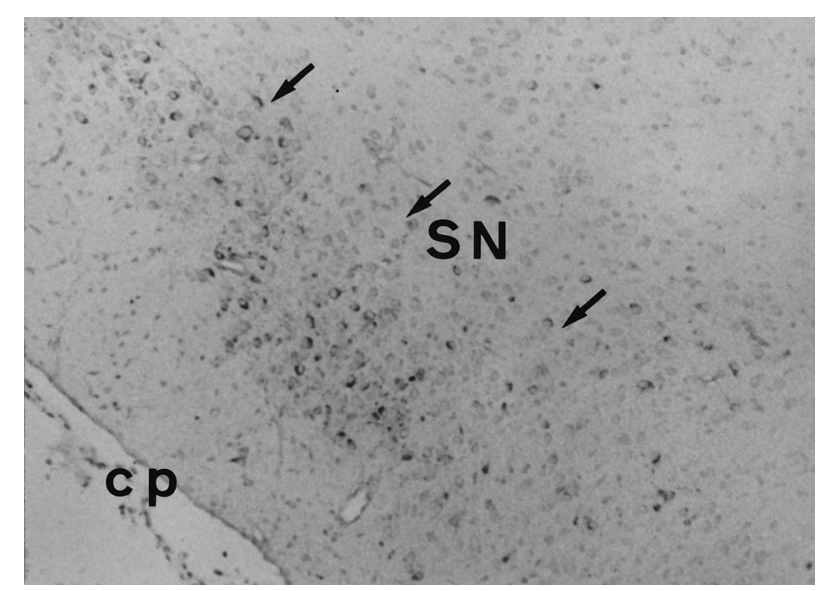

Figure 1 Immunohistochemical staining with anti-Japanese encephalitis virus (JEV) antibody in the midbrain of a rat sacrificed 3 days after JEV infection at the age of 13 days $(\times 100)$. Photomicrograph of a coronal section through the brain of the rat shows dense accumulation of JEV antigen in the neurons of the substantia nigra (arrows). cp, cerebral peduncle; SN, substantia nigra. less affected (Figure 2a and b). In the infected rats, the neuronal loss was also associated with marked gliosis in the zona compacta region (Figure 2c) compared to control animals (Figure 2d). Immunohistochemical analysis with anti-tyrosine hydroxylase (TH) antibody showed that the number of $\mathrm{TH}-$ positive neurons was also significantly less in the substantia nigra (Figure 3a) compared to that in controls (Figure 3c). However, equivalent numbers of TH-positive neurons were found in the caudate putamen in JEV-infected rats (Figure $3 \mathrm{~b}$ ) as well as in age-matched control rats (Figure $3 \mathrm{~d}$ ). These pathologic findings suggest there is a selective vulnerability of neurons of the substantia nigra and to a lesser extent caudate putamen of rats to the destructive effects of JEV following intracerebral inoculation. In the JEV-infected rat brains, the same pathologic features were found in greater than $80 \%$ of the animals examined (25/30). Moreover in rats sacrificed 1 year after JEV inoculation, almost no TH-positive neurons could be found in the substantia nigra (data not shown). The latter observation might suggest that the dopaminergic system function may deteriorate even further with age. Although no Lewy bodies or locus ceruleus lesions were observed, and immunohistochemical staining with an ant-tau antibody was negative (unpublished data), the distribution of the pathological lesions in the substantia nigra found in JEV-treated rats was remarkably similar to that in Parkinson's disease.

Tissue distribution of the JEV genome by RT-PCR Using RT-PCR and cerebral cortex tissue samples from rats infected with JEV at age 5 days and sacrificed 5 days later, JEV genomic RNA could be readily detected under the conditions employed (Figure 4, lane 1). Similarly in rats infected with JEV at age 13 days, the cerebral cortex (lane 2) and the substantia nigra (lane 3) taken from the rats sacrificed 5 days later also contained JEV genomic RNA. In both the negative controls (not shown) and the cerebral cortex (lane 4) where no abnormal neuropathologic changes could be found, JEV RNA was not detected. Despite the histopathological changes JEV genome was also not detected in the substantia nigra (lane 5). These results suggest that there was no persistent infection by JEV in these tissues. In these studies only one primer pair was used for detection of genomic RNA. As the JEV genome is a single stranded RNA molecule the employment of additional primers would not be expected to produce different findings from those just described.

\section{Motor function}

The motor activity of the adult rats infected with JEV at age 13 days, was tested 12 weeks later and compared to age-matched control rats. The time required for the pole test was $18.3 \pm 4.3 \mathrm{~s}(n=10)$ for the JEV-infected rats before L-DOPA treatment, 
a

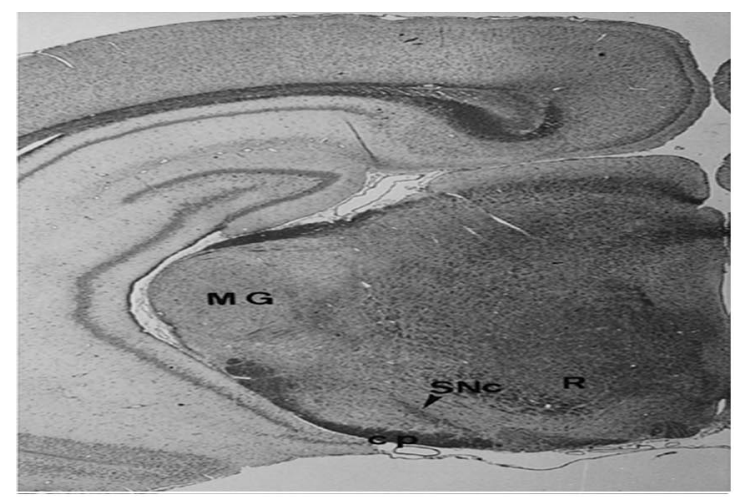

C

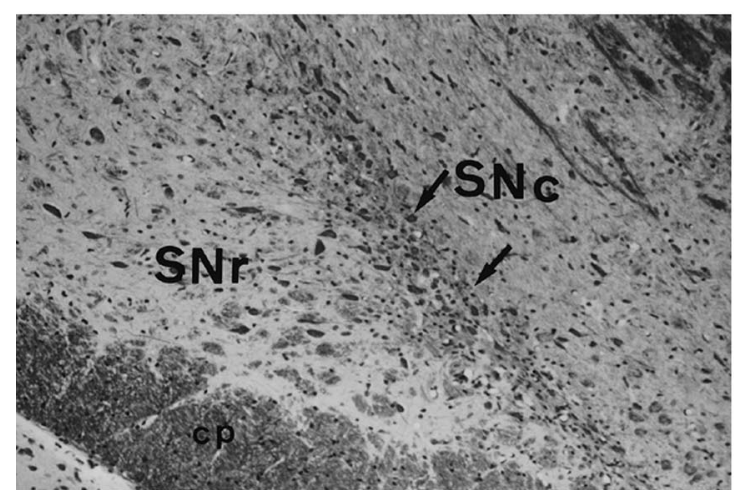

b

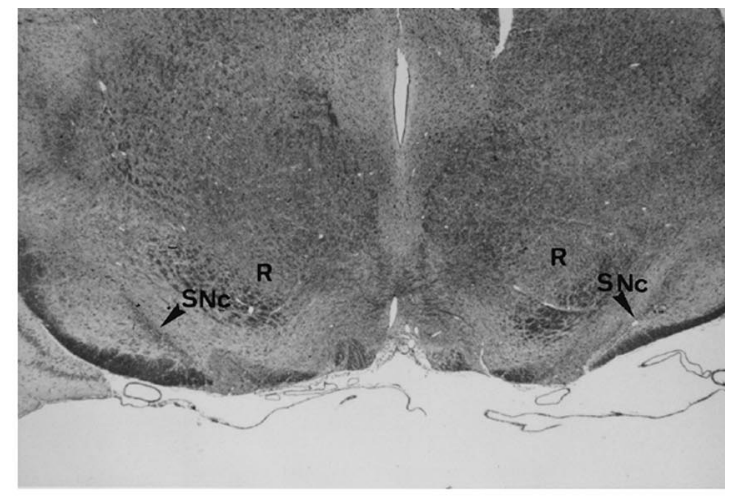

d

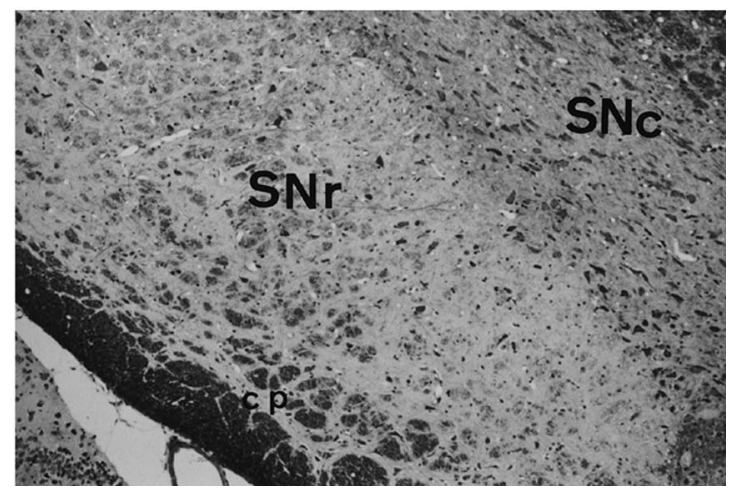

Figure 2 Coronal section of the brain of a rat sacrificed 12 weeks after JEV infection at the age of 13 days (a,b,c) and an age-matched control rat (d) (Klüver-Barrera stain). (a) The neuronal loss (arrowhead) is confined mainly to the zona compacta of the substantia nigra, without lesions in the cerebral cortex. The most severe lesions are in the central part of the zona compacta $(\times 20)$. (b) Photomicrograph of the same section reveals the bilateral lesions of the substantia nigra (arrowheads) $(\times 30)$. (c) High power view $(\times 165)$ of the substantia nigra in the JEV-infected rat shows marked neuronal loss with gliosis in the zona compacta (arrows), in contrast to that of the control rat (d). cp, cerebral peduncle; MG, medial geniculate nucleus; R, red nucleus; SNc, substantia nigra zona compacta; SNr, substantia nigra zona reticulata.

$6.5 \pm 1.4 \mathrm{~s}(n=14)$ for the control rats, and $8.3 \pm 2.6 \mathrm{~s}$ $(n=10)$ for the JEV-infected rats after treatment with L-DOPA. The difference between the JEV-infected rats and the control rats was significantly $(P<0.001$, Figure 5). The pole test results are consistent with marked bradykinesia observed in the JEV-infected affected rats. Unfortunately other clinical features seen in human disease such as masked facies or tremor could not be assessed in the infected animals.

\section{Discussion}

The pathogenesis of Parkinson's disease is poorly understood but is almost certainly multifactorial involving genetic, environmental and possibly infectious components (Calne and Langston, 1983; Burns et al, 1983; Ballard et al, 1985; Cohen, 1986; Riederer et al, 1989; Dexter et al, 1989; Adams and Odunze, 1991; Nagatsu and Yoshida, 1988; Yoshida et al, 1990). With regard to the latter, a number of viruses have been shown to selectively infect the substantia nigra and induce parkinsonism (Kristensson, 1992; Duvoisin and Yahr, 1965). Postencephalitic parkinsonism has been well documented (von Economo, 1917; Yahr, 1978) and the world pandemic of encephalitis lethargica, von Economo encephalitis, from 1916 to 1927 resulted in the death or disability of approximately half a million people. In addition there have been individual case reports describing the association of different viruses with this disorder. These have included a 54-year-old woman who manifested symptoms of parkinsonism while convalescing from meningoencephalitis due to Coxsackie B virus (Walters, 1960) and similar processes have been described following influenza A (Hudson and Rice, 1990), poliovirus (Bojinov 1971) and measles virus (Alves et al, 1992) infections. The possible involvement of virus infection has also been supported by experimental animal models, Fishman et al. (1985) reported a selective attack on the substantia nigra and subthalamic nucleus by a strain of mouse hepatitis virus, and more recently similar features have been 
a

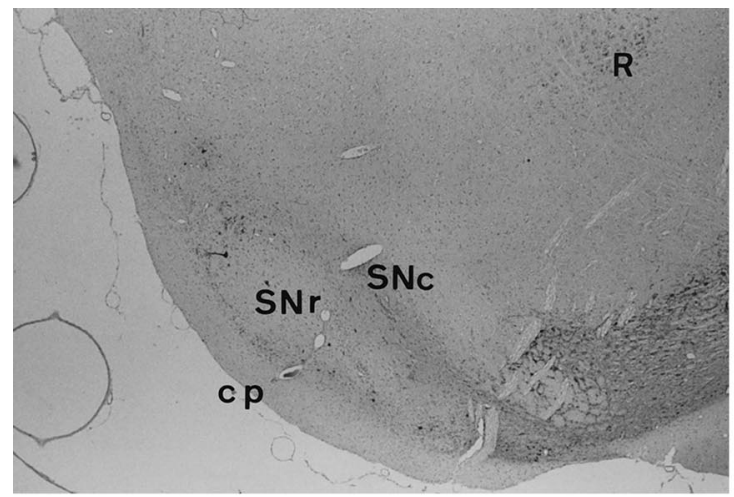

C

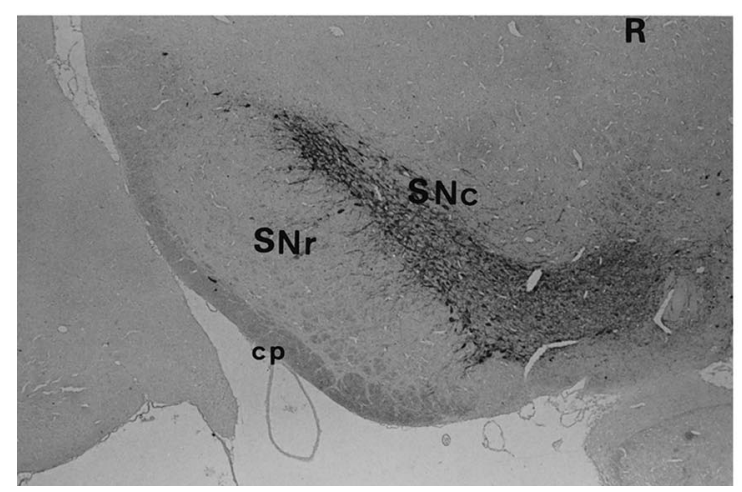

b

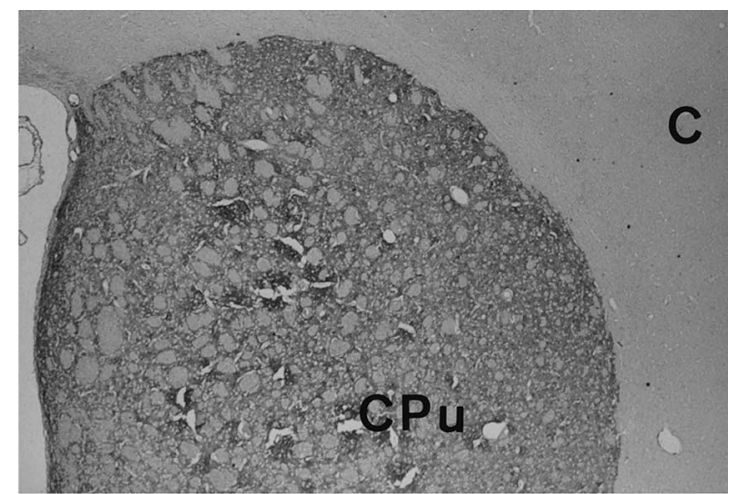

d

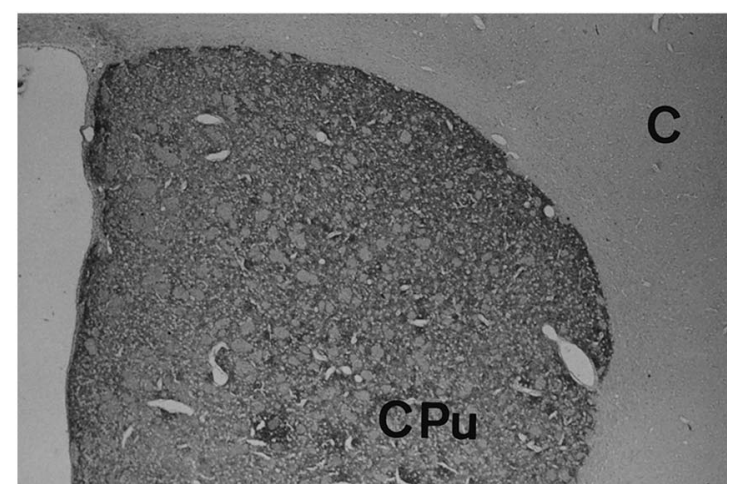

Figure 3 Immunohistochemical study of the substantia nigra and caudate-putamen with anti-tyrosine hydroxylase (TH) antibody in JEV-infected rat $(\mathrm{a}, \mathrm{b} \times 40)$ sacrificed 12 weeks after JEV infection at the age of 13 days and an age-matched control rat $(\mathrm{c}, \mathrm{d} \times 40)$. THpositive neurons in JEV-infected rats (a) are decreased in number in the substantia nigra compared with those in a control rat (c), whereas numerous TH-positive neurons are found in the caudate putamen in JEV-infected rats (b) as well as a control rat (d). C, cerebral cortex; $\mathrm{CPu}$, caudate putamen; $\mathrm{cp}$, cerebral peduncle; $\mathrm{R}$, red nucleus; SNc, substantia nigra zona compacta; SNr, substantia nigra zona reticulata.

described in rats infected with influenza virus (Takahashi et al, 1995). In the present study we have demonstrated pathological and to a certain extent clinical features consistent with Parkinson's disease following infection of rats with JEV. The JEV induced parkinsonism in rats is characterized by selective destruction of neurons in the substantia nigra, bilaterally, and particularly in the region of the zona compacta with an associated loss of $\mathrm{TH}$ producing cells in this region. Attempts to detect JEV using immunohistochemistry or by RT - PCR to amplify the NS3 region of the JEV genome showed that genomic RNA could not be detected in affected rats sacrificed 12 weeks after initial infection. In contrast reactions under identical conditions on control samples readily allowed the detection of genome in control tissues. These findings suggest that in our animal model there does not appear to be a persistent or chronic JEV infection.

The immunohistochemical data obtained also suggested that the function of the dopaminergic system may progressively deteriorate with age in the absence of ongoing or persistent JEV infection.
McGeer et al (1988) showed that the rate of neuronal cell degeneration was considerably higher in Parkinsonian patients than could be accounted for on the basis of normal age-related neuronal degeneration alone. It seems that neuronal cell degeneration in our model may also have progressed more rapidly in the JEV-treated rats than in the controls. This observation raises the possibility that postencephalitic parkinsonism as well as Parkinson's disease could be a continuing degenerative process rather than an acute illness on which the effects of aging or decompensation are superimposed (Gibb and Lees, 1987; Geddes et al, 1993).

JEV infection is the most common cause of arthropod-borne human encephalitis worldwide, and infection has also been associated with postencephalitis parkinsonism syndrome in man (Goto, 1962; Dickerson et al, 1952; Richter and Shimojyo, 1916; Shoji et al, 1993). Dickerson et al (1952), in a study of 200 acute cases of Japanese encephalitis, noted tremors primarily involving the fingers, tongue and eyelids in $90 \%$, muscular rigidity in greater than $40 \%$, and a mask-like face is in $75 \%$ of 


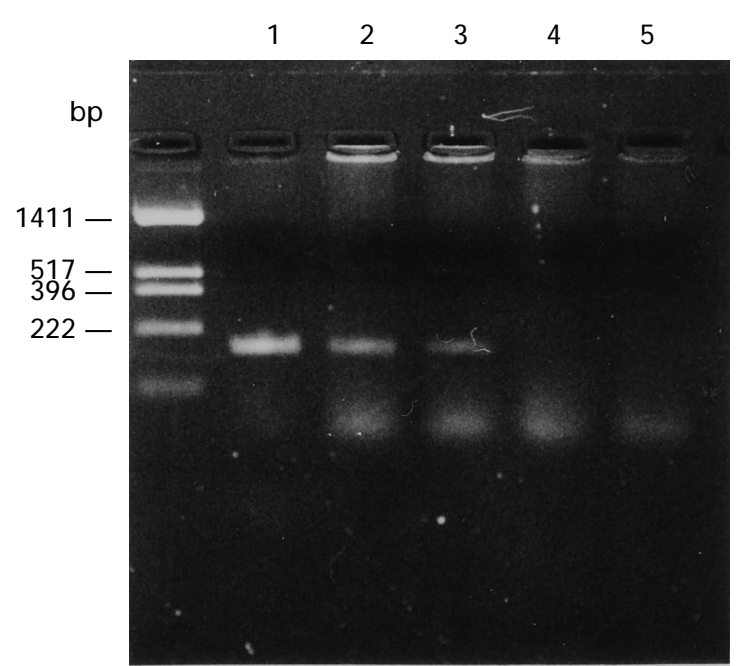

Figure 4 Reverse transcription-polymerase chain reaction of JEV-amplified NS3 sequences from JEV-infected brains. The cerebral cortex (lane 1) from rats sacrificed 5 days after JEV infection at the age of 5 days is used as positive control. In rats infected with JEV at the age of 13 days, the JEV genome can be detected in the cerebral cortex (lane 2) and the substantia nigra (lane 3) taken from rats sacrificed 5 days after infection, whereas it is undetectable in both the cerebral cortex (lane 4) and the substantia nigra (lane 5) taken from rats sacrificed 12 weeks after infection.

the cases. Goto (1962) detected parkinsonian sequelae in $11.6 \%$ of 143 unselected patients 5 years after they had Japanese virus encephalitis. The parkinsonian syndrome following Japanese encephalitis appears to differ from that following encephalitis lethargica in several respects. In general, parkinsonism after Japanese encephalitis is mild, develops in the acute phase, and occasionally improves slightly over a long period. However these clinical observations together with our rat model might suggest the involvement of JEV in certain cases.

It remains unclear why the neurons of the substantia nigra remain susceptible to JEV infection as opposed to other regions of the brain (Ogata et al, 1991; Kimura-Kuroda et al, 1993). One possibility is that virus receptors on the substantia nigra neurons persist longer than in other CNS structures. Certainly, the capacity of viruses to attack specific tissues selectively depends on an interaction between viral genes or proteins and host factors. Immune mechanisms (Appel et al, 1992) following an infection or other factors could also be associated with the destruction of the substantia nigra. Further studies on the tropism of JEV for the substantia nigra in this experimental model might reveal mechanisms that are involved in the degeneration of nigral dopaminergic neurons that is central to this disease.

Finally, although it was difficult to assess the clinical status of our infected animals significant behavioral improvement was observed upon administration of L-DOPA. The pole test employed in

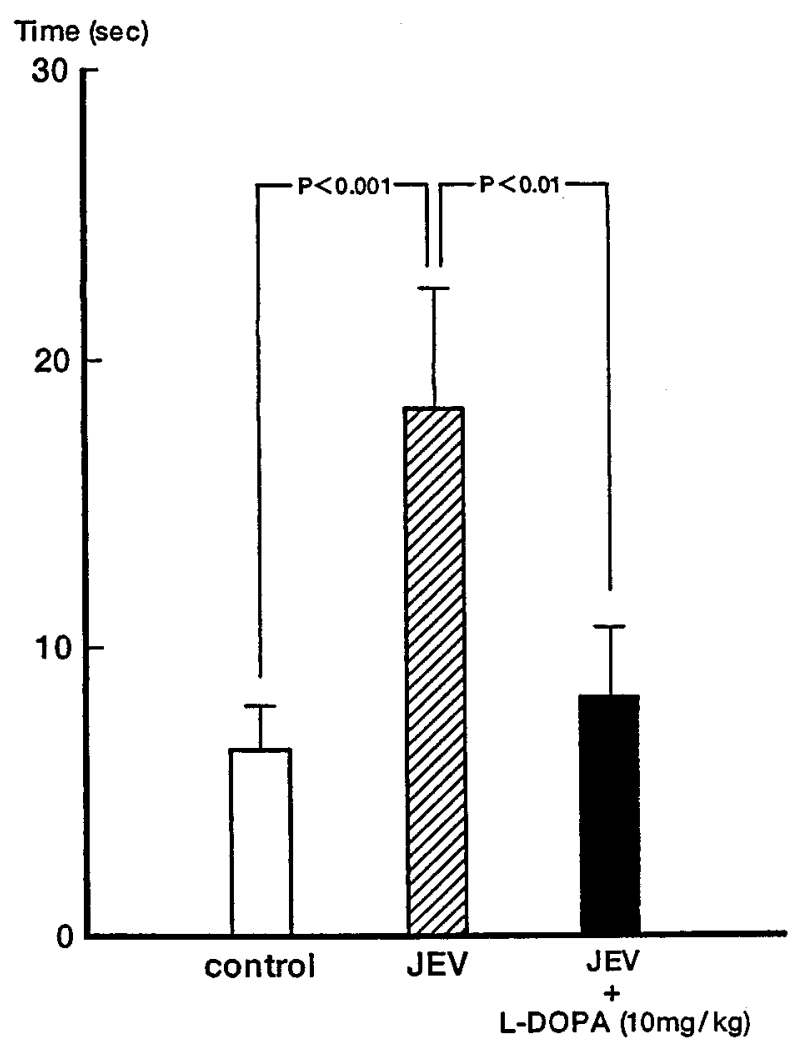

Figure 5 Assessment of motor activity in age-matched controls $(n=14)$, JEV-treated rats $(n=10)$ and the same JEV-treated rats after L-DOPA treatment $(n=10)$. Significant behavioral improvement by L-DOPA is observed.

these studies appears to be useful in assessing clinical status and response to therapy. Accordingly, this JEV-induced parkinsonian model might be important not only in studies of the pathogenesis of this disease but possibly useful in the assessment of new anti-parkinsonian drugs, and perhaps in the efficiency of neuronal transplantation therapy.

\section{Materials and methods}

\section{Animals and virus}

Albino rats of the Fischer strain were obtained from SLC Japan. The virus strain used was the JaGAr-01 strain of JEV. Supernatants from 10\% homogenates of infected mouse brains $\left(10^{9} \mathrm{PFU} / \mathrm{ml}\right)$ were diluted with $20 \%$ Hemacel (Hoechst) in Eagle's minimum essential medium and stored at $-70^{\circ} \mathrm{C}$ until use. Virus ( $0.03 \mathrm{ml}$ containing $3 \times 10^{6} \mathrm{PFU}$ ) was inoculated intracerebrally with a specially designed twostep thin 27 gauge needle (Hoshimori Iryoki KK, Tokyo, Japan) with a stopper $3 \mathrm{~mm}$ from the tip. The site of inoculation was located at the midpoint of the line connecting the left eye to the midpoint between the right and left ears. Hemacel $(20 \%)$ in Eagle's minimum essential medium was injected into control rats. 
Neuropathologic studies

The neuropathologic changes in rats infected with JEV on days 12, 13 and 14 after birth were examined. In each case animals were sacrificed at 3 days, 10 days, 12 weeks or 1 year after inoculation under ether anesthesia by perfusion fixation via the aorta with $4 \%$ freshly prepared paraformaldehyde in $0.1 \mathrm{M}$ phosphate buffer. Coronal brain sections were taken from the frontal tip to the medulla, embedded in paraffin, and stained with hematoxylin-eosin, Luxol fast blue-cresyl violet (KlüverBarrera method), anti-JEV antibody and anti-tyrosine hydroxylase (TH) monoclonal antibody (Chemicon). The avidin-biotin-peroxidase complex (ABC) method was used in all immunohistochemical studies (Hsu et al, 1981). After deparaffinization, the specimens were treated with $0.3 \% \mathrm{H}_{2} \mathrm{O}_{2}$ methanol to suppress endogenous peroxidase activity, incubated with $10 \%$ normal goat serum, and allowed to react with anti-JEV rabbit serum or anti$\mathrm{TH}$ monoclonal antibody, diluted in $1 \%$ bovine serum albumin (BSA) at $4{ }^{\circ} \mathrm{C}$ overnight. Incubations with only $1 \%$ BSA were used as negative controls. The sections reacted with anti-JEV antibody and anti-TH monoclonal antibody were reacted with biotinylated goat anti-rabbit IgG and biotinylated goat anti-mouse IgG respectively. ABC reaction products were visualized with 3,3'-diaminobenzidine tetrahydrochloride (Sigma) and counterstained with hematoxylin.

\section{Reverse transcription-polymerase chain reaction} (RT-PCR)

Primers used in RT-PCRs were $5739-5^{\prime}$-AGAGCGGGGAAAAAGGTCAT-3'-5758 (sense) and 5900- $\quad 3$ '-TTTCACGCTCTTTCTACAGT-5'- 5881 (antisense) which permitted amplification of the NS3 region of the JEV genome (Sumiyoshi et al, 1987). Oligonucleotides were synthesized on a Cyclone Plus DNA/RNA synthesizer (Millipore Co., Japan). Prior neuropathological and immunohistochemical studies (Ogata et al, 1991) demonstrated that rats infected with JEV on days 5 after birth had a severe panencephalitis with readily detectable JEV antigen. Thus, brains taken from 3 rats inoculated with JEV on days 5 after birth and sacrificed 5 days later were used as positive controls. Cerebral cortex taken from an uninfected normal rat brain was used as a negative control. Rats

\section{References}

Adams JD, Odunze IN (1991). Oxigen free radicals and Parkinson's disease. Free Radical Biol Med 10: 161 169.

Alves RSC, Barbosa ER, Scaff M (1992). Postvaccinial parkinsonism. Movement Disorders 7: 178-180.

Appel SH, Le W-D, Tajti J, Haverkamp LJ, Engelhardt JI (1992). Nigral damage and dopaminergic hypofunction in mesencephalon-immunized guinea pigs. Ann Neurol 32: 494-501. infected with JEV on day 13 of life were sacrificed at 5 days (3 rats) or 12 weeks (3 rats) later. Pieces of the cerebral cortex and the ventral region of the midbrain were taken from each animal using a magnifying microscope. In all 100 milligrams of brain tissue was added to $1 \mathrm{ml}$ PBS and homogenized with a Polytron. $5 \mu \mathrm{l}$ of this homogenate were then incubated with an equal volume of detergent mix (2\% NP-40, $10 \mathrm{U}$ of RNase inhibitor (Takara Co., Kyoto, Japan) in PBS) in a $500 \mathrm{ml}$ Eppendorf-type tube for $1 \mathrm{~min}$ at room temperature. This was added to $90 \mu \mathrm{l}$ of RT - PCR mix (100 pmol of each primer, $0.2 \mathrm{mM}$ deoxynucleoside triphosphate, $10 \mathrm{mM}$ Tris ( $\mathrm{pH}$ 8.9), $1.5 \mathrm{mM} \mathrm{MgCl}_{2}, 80 \mathrm{mM}$ $\mathrm{KCl}, 0.5 \mathrm{mg}$ of BSA per $\mathrm{ml}, 0.1 \%$ sodium cholate, $0.1 \%$ Triton $\mathrm{X}-100,10 \mathrm{U}$ of reverse transcriptase (Takara Co., Kyoto, Japan) and $2 \mathrm{U}$ of Th-DNA polymerase, a thermostable DNA polymerase (Toyobo Co., Osaka, Japan). The reaction mixture was incubated for $10 \mathrm{~min}$ at $53^{\circ} \mathrm{C}$ for the RT reaction. PCR amplification $\left(92^{\circ} \mathrm{C}\right.$ for $60 \mathrm{~s}, 53^{\circ} \mathrm{C}$ for $90 \mathrm{~s}$ and $72^{\circ} \mathrm{C}$ for $120 \mathrm{~s}$ using a PC-700 thermal cycler (Astec Co., Fukuoka, Japan) was started immediately after the RT step and continued for 35 cycles (Morita et al, 1991). PCR products were separated on a $3 \%$ agarose gels and after electrophoresis were visualized by ethidium bromide staining. Amplification produced a 142 bp fragment.

\section{Assessment of motor function}

A pole test (Ogawa et al, 1985) was performed as a way of evaluating bradykinesia in the infected rats. The time for the rats to descend from the top of a rough-surfaced pole $(2.5 \mathrm{~cm}$ in diameter and $100 \mathrm{~cm}$ in height) to the floor was recorded in JEVinfected adult rats and adult controls. To assess the efficiency of L-DOPA, the same procedure was repeated immediately after the successive intraperitoneal injection of L-DOPA $(10 \mathrm{mg} / \mathrm{kg} / \mathrm{day})$ for 7 days. Comparisons among mean values for groups were done by Student's t test.

\section{Acknowledgements}

We thank Kenichi Nakase for his technical assistance.

Ballard PA, Tetrud JW, Langston JW (1985). Permanent human parkinsonism due to 1-methyl-4-phenyl1,2,3,6-tetrahydropyridine (MPTP): seven cases. Neurology 35: 949-956.

Bojinov S (1971). Encephalitis with acute parkinsonian syndrome and bilateral inflammatory necrosis of the substantia nigra. J Neurol Sci 12: 383-415. 
Burns RS, Chiueh CC, Markey SP, Ebert MH, Jacobowitz DM, Kopin IJ (1983). A primate model of parkinsonism: Selective destruction of dopaminergic neurons in the pars compacta of the substantia nigra by N-methyl-4-phenyl-1,2,3,6-tetrahydropyridine. Proc Natl Acad Sci USA 80: 4546-4550.

Calne DB, Langston JW (1983). Aetiology of Parkinson's disease. Lancet ii: 1457-1459.

Chiueh CC, Markey SP, Burns RS et al (1983). N-methyl4-phenyl-1,2,3,6-tetrahydropyridine, a parkinsonian syndrome causing agent in man and monkey, produces different effects in guinea pig and rat. Pharmacologist 25: 131.

Cohen G (1986). Monoamine oxidase, hydrogen peroxidase and Parkinson's disease. Adv Neurol 45: $119-125$.

Dexter DT, Wells FR, Lees AJ, et al (1989). Increased nigral iron content and alterations in other metal ions occurring in brain in Parkinson's disease. $J$ Neurochem 52: 1830-1836.

Dickerson RB, Newton JR, Hansen JE (1952). Diagnosis and immediate prognosis of Japanese B encephalitis. Am J Med 12: 277-288.

Duvoisin RC, Yahr MD (1965). Encephalitis and parkinsonism. Arch Neurol 12: 227-239.

Fishman PS, Gass JS, Swoveland PT, Lavi E, Highkin MK, Weiss SR (1985). Infection of the basal ganglia by a murine coronavirus. Science 229: $877-879$.

Geddes JF, Hughes AJ, Lees AJ, Daniel SE (1993). Pathological overlap in cases of parkinsonism associated with neurofibrillary tangles. A study of recent cases of postencephalitic parkinsonism and comparison with progressive supranuclear palsy and Guamanian parkinsonism-dementia complex. Brain 116: $281-302$.

Gibb WRG, Lees AJ (1987). The progression of idiopathic Parkinson's disease is not explained by age-related changes. Clinical and pathological comparisons with post-encephalitic parkinsonian syndrome. Acta Neuropathol (Berl) 73: 195-201.

Goto A (1962). Follow-up study of Japanese B encephalitis. Psychiat Neurol Jpn (Tokyo) 64: 236266.

Heikkila RE, Hess A, Duvoisin RC (1984). Dopaminergic neurotoxicity of 1-methyl-4-phenyl-1,2,5,6-tetrahydropyridine in mice. Science 224: 1451-1453.

Hsu SM, Raine L, Fanger H (1981). Use of avidin-biotinperoxidase complex (ABC) in immunoperoxidase techniques: a comparison between $\mathrm{ABC}$ and unlabeled antibody (PAP) procedures. J Histochem Cytochem 29: 577-580.

Hudson AJ, Rice GPA (1990). Similarities of Guamanian ALS/PD to post-encephalitic parkinsonism/ALS: possible viral cause. Can J Neurol Sci 17: 427-433.

Kelly PH, Seviour PW, Iversen SD (1975). Amphetamine and apomorphine responses in the rat following 6OHDA lesions of the nucleus accumbens septi and corpus striatum. Brain Research 94: 507-522.

Kimura-Kuroda J, Ichikawa M, Ogata A, Nagashima K, Yasui K (1993). Specific tropism of Japanese encephalitis virus for developing neurons in primary rat brain culture. Arch Virol 130: 477-484.
Kristensson K (1992). Potential role of viruses in neurodegeneration. Molecular and Chemical Neuropathology 16: $45-58$.

Langston JW, Ballard P, Tetrud JW, Irwin I (1983). Chronic parkinsonism in humans due to a product of meperidine-analog synthesis. Science 219: 979-980.

Langston JW (1989). Current theories on the cause of Parkinson's disease. J Neu Neurosurg Psychiatry 52: $13-17$.

McGeer PL, Itagaki S, Akiyama H, McGeer EG (1988). Rate of cell death in parkinsonism indicates active neuropathological process. Ann Neurol 24: 574-576.

Morita K, Tanaka M, Igarashi A (1991). Rapid identification of dengue virus serotypes by using polymerase chain reaction. J Clin Microbiol 29: $2107-2110$.

Nagatsu T, Yoshida M (1988). An endogenous substance of the brain, tetrahydroisoquinoline, produces parkinsonism in primate with decreased dopamine, tyrosine hydroxylase and biopterin in the nigrostriatal regions. Neurosci Lett 87: 178-182.

Ogata A, Nagashima K, Hall WW, Ichikawa M, KimuraKuroda J, Yasui K (1991). Japanese encephalitis virus neurotropism is dependent on the degree of neuronal maturity. J Virol 65: 880-886.

Ogawa N, Hirose Y, Ohara T, et al (1985). A simple quantitative bradykinesia test in MPTP-treated mice. Res Commun Chem Pathol Pharmacol 50: 435-441.

Richter RW, Shimojyo S (1961). Neurologic sequelae of Japanese B encephalitis. Neurology 11: 553-559.

Riederer P, Sotic E, Rausch WD, et al (1989). Transition metals ferritin, glutathione and ascorbic acid in Parkinsonian brain. J Neurochem 52: 515-520.

Shoji $\mathrm{H}$, Watanabe $\mathrm{M}$, Itoh $\mathrm{S}$, Kuwahara $\mathrm{H}$, Hattori $\mathrm{F}$ (1993). Japanese encephalitis and parkinsonism. J Neurol 240: 59-60.

Sumiyoshi H, Mori C, Fuke I, et al (1987). Complete nucleotide sequence of the Japanese encephalitis virus genome RNA. Virology 161: 497-510.

Takahashi M, Yamada T, Nakajima S, Nakajima K, Yamamoto T, Okada H (1995). The substania nigra is a major target for neurovirulent influenza A virus. $J$ Exp Med 181: 2161-2169.

Vingerhoets FJG, Snow BJ, Tetrud JW, Langston JW, Schulzer M, Calne DB (1994). Positron emission tomographic evidence for progression of human MPTP-induced dopaminergic lesions. Ann Neurol 36: $765-770$

von Economo C (1917). Encephalitis lethargica. Wien klin Wschr 30: 581-585.

Walters JH (1960). Post-encephalitic parkinson syndrome after meningoencephalitis due to coxsackie virus group B, type 2. New Eng J Med 263: 744-747.

Yahr MD (1978). Encephalitis lethargica (Von Economo's disease, epidemic encephalitis). In: Handbook of clinical neurology, Vinken PJ, Bruyn GW, (eds.) volume 34. Amsterdam: North-Holland, pp 451-457.

Yoshida M, Miwa T, Nagatsu T (1990). Parkinsonism in monkeys produced by chronic administration of an endogenous substance of the brain, tetrahydroisoquinoline: the behavioral and biochemical changes. Neurosci Lett 119: 109-113. 